\title{
Waterpipe smoke condensate influences epithelial to mesenchymal transition and interferes with the cytotoxic immune response in non-small cell lung cancer cell lines
}

\author{
RANIA FAOUZI ZAAROUR ${ }^{1}$, PRATHIBHA PRASAD ${ }^{1}$, GOUTHAM HASSAN VENKATESH ${ }^{1}$, \\ RAEFA ABOU KHOUZAM ${ }^{1}$, FRANCIS AMIRTHARAJ ${ }^{1}$, NAGWA ZEINELABDIN ${ }^{1}$, AYESHA RIFATH ${ }^{1}$, \\ STEPHANE TERRY ${ }^{2}$, HUSAM NAWAFLEH ${ }^{1}$, YEHYA EL SAYED ${ }^{3}$ and SALEM CHOUAIB ${ }^{1,2}$ \\ ${ }^{1}$ Thumbay Research Institute for Precision Medicine, Gulf Medical University, Ajman 4184, UAE; \\ ${ }^{2}$ INSERM UMR 1186, Integrative Tumour Immunology and Immunotherapy, Gustave Roussy, Faculty of Medicine - \\ University of Paris-Sud, University of Paris-Saclay, F-94805 Villejuif, France; ${ }^{3}$ Department of Biology, \\ Chemistry and Environmental Sciences (BCE), American University of Sharjah, Sharjah 26666, UAE
}

Received March 13, 2020; Accepted October 12, 2020

DOI: $10.3892 /$ or.2021.7938

\begin{abstract}
Waterpipe tobacco smoking (WPS) continues to spread globally and presents serious health hazards. The aim of the present study was to investigate the effects of treatment with WPS condensate (WPSC) on lung cell proliferation and plasticity as well as tumor cell recognition and killing by natural killer (NK) cells using cytotoxicity assays. The results indicated that exposure of normal and cancer lung cell lines to WPSC resulted in a decrease in their in vitro growth in a dose-dependent manner and it induced tumor senescence. In addition, WPSC selectively caused DNA damage as revealed by an increase in $\gamma \mathrm{H} 2 \mathrm{AX}$ and 53BP1 in tumor lung cells. To gain further insight into the molecular mechanisms altered by WPSC, we conducted a global comprehensive transcriptome analysis of WPSC-treated tumor cells. Data analysis identified an expression profile of genes that best distinguished treated and non-treated cells involving several pathways. Of these pathways, we focused on those involved in epithelial to mesenchymal transition (EMT) and stemness. Results showed that WPSC induced an increase in SNAI2 expression associated with EMT, ACTA2 and SERPINE2 were involved in invasion and $C D 44$ was associated with stemness. Furthermore, WPSC
\end{abstract}

Correspondence to: Dr Rania Faouzi Zaarour, Thumbay Research Institute for Precision Medicine, Gulf Medical University, P.O. Box 4148, Ajman 4184, UAE

E-mail: dr.rania@gmu.ac.ae

Abbreviations: WPS, waterpipe smoke; WPSC, waterpipe smoke condensate; EMT, epithelial to mesenchymal transition; NK, natural killer

Key words: waterpipe smoke, lung cancer, epithelial to mesenchymal transition, cancer stem cells, inflammation, tumor microenvironment, natural killer-mediated cytotoxicity exposure increased the expression of inflammatory response genes including CASP1, ILIB, IL6 and CCL2. While immune synapse formation between NK and WPSC-treated lung cancer target cells was not affected, the capacity of NK cells to kill these target cells was reduced. The data reported in the present study are, to the best of our knowledge, the first in vitro demonstration of WPSC effects on lung cellular parameters providing evidence of its potential involvement in tumor physiology and development.

\section{Introduction}

Smoking is the leading cause of chronic obstructive pulmonary disease, a progressive and eventually debilitating lung disease (1). Furthermore, smokers of tobacco are 20-40 times more at risk of developing lung cancer in comparison to nonsmokers (2).

Tobacco can be smoked using different ways, two common ways include the use of cigarettes or waterpipes. Several studies have investigated the chemical composition of cigarette smoke and more than 5,000 bioactive chemical compounds have been isolated, including over 60 carcinogens (3). Waterpipe smoke analysis has revealed that it contains significant concentrations of toxicants including 27 known or suspected carcinogens thought to cause dependence, heart disease, lung disease and cancer (4). Despite the adverse health effects among users, waterpipe usage is growing in popularity and public health interventions remain below what is present for cigarette smoking (5).

Several studies have addressed the in vivo effects of WPS on waterpipe smokers' health. Smokers are found to have high urinary concentrations of several toxins including carcinogens (6), resulting in profound effects on lung function (7). Waterpipe smokers were also observed to have 6-fold greater risk of developing lung cancer (8). At the molecular level, DNA repair gene expression was reported to be decreased in the blood of waterpipe smokers, while DNA damage-related gene expression was increased (9). It has also been reported 
that WPS induces endothelial cell dysfunction, inflammation, and impaired repair mechanisms with implication in vascular disease (10). In this respect, nicotine, present in WPS, induces bronchial epithelial cell apoptosis and senescence via ROS-mediated autophagy-impairment (11). WPSC also induces cell cycle arrest and cellular senescence mediated by the p53-p21 pathway in alveolar type 2 cell disease (10), whereas it induces apoptosis in human aortic endothelial cells $(10,12)$. All these data highlight the damaging effects of WPS. More importantly, WPS may contribute towards EMT, tumor heterogeneity and immune escape. These processes are known to play critical roles in tumor plasticity and are important factors impacting both the diagnosis and treatment of cancer patients (13).

The aim of the present study examined the changes in tumor lung cell gene expression related to DNA damage, inflammation, EMT and stemness. In addition, the consequence of WPSC treatment on immune recognition and killing by NK cells was investigated. Our results emphasized the potential impact of WPSC on tumor lung cell behavior and provide insights into their associated transcriptomic response including DNA damage, inflammation, and cell plasticity.

\section{Materials and methods}

Waterpipe smoke sampling and analysis. Waterpipe smoke collection was performed as previously described (14). Briefly, $17.5 \mathrm{~g}$ double apple flavor tobacco (mou'assal) was placed in the head piece of the waterpipe which was then tightly wrapped using a perforated aluminum foil. Two pieces of quick lighting charcoal briquettes were used to heat the tobacco. The generated smoke was collected using a robotic machine (IREADY LLC) that simulates the human smoking process. The puff duration was set at $5 \mathrm{sec}$ per puff with $15 \mathrm{sec}$ inter-puff duration, for a total of 80 puffs per session. Collection of the smoke condensate was carried out on pre-conditioned glass wool fibers packed inside a T-shaped tube. It is important to note that under our experimental conditions, the cells were exposed to the waterpipe smoke condensate samples. To identify the chemical composition of the condensate and to eliminate any masking effect of the large glycerin peak during gas chromatography-mass spectrometry (GC-MS), successive extraction steps were performed. The extraction procedure was carried out by mixing $72.6 \mathrm{mg}$ of the extract in $4 \mathrm{ml}$ of toluene. The mixture was stirred for $24 \mathrm{~h}$ and allowed to separate. In this step, glycerin is not expected to move into the toluene layer. Then, $0.15 \mathrm{ml}$ of the remaining components of the extract were dissolved in $15 \mathrm{ml}$ of ethanol followed by a dilution of 1:40 in ethanol prior to gas chromatography mass spectrometry (GCMS) analysis to eliminate detector saturation. Specifically, $2 \mathrm{ml}$ of toluene was added to the smoke condensate $(20 \mathrm{ml})$, agitated for $2 \mathrm{~h}$ on an orbital shaker (Z206A), and spun at $100 \mathrm{x} \mathrm{g}$ for $5 \mathrm{~min}$ at room temperature. The toluene was then separated prior to dissolving in $2 \mathrm{ml}$ ethanol which was used for the GCMS analysis. It is worth noting that reproducibility was assured by using internal standards. Tridecane and 1-octadecene were used as internal standards for toluene extract while dibutyl phthalate was used for ethanol solution prior to GCMS analysis. The toluene and ethanol extract were labelled as 'toluene' and 'toluene-ethanol', respectively. The toluene and ethanol solutions were then analyzed using GCMSQP2010 Ultra instrument (Shimadzu Corporation). Rtx-5MS capillary column (30 $\mathrm{m}$ in length, $0.25 \mu \mathrm{m}$ in thickness, and a diameter of $0.25 \mathrm{~mm}$ ) was used. The column oven temperature was held at $40^{\circ} \mathrm{C}$ for 3 min then ramped at a rate of $5^{\circ} \mathrm{C}$ per min to $300^{\circ} \mathrm{C}$ where it was held constant for $15 \mathrm{~min}$. Helium was used as the carrier gas at a column flow of $1.0 \mathrm{ml} / \mathrm{min}$. The safety, hazard and toxicity evaluation of the toluene and ethanol extracts was performed using ToxNet and PubChem resources.

Cell culture and proliferation assay. A549 (gift from Professor Fathia Mami Chouaib, Gustave Roussy, Villejuif Cedex, France; RRID:CVCL_0023) and H460 cells (AddexBio C0016003 RRID:CVCL_0459) were grown in complete RPMI-1640 medium, (cat. no. 61870010; Gibco; Thermo Fisher Scientific, Inc.) supplemented with $10 \%$ heatinactivated fetal bovine serum (cat. no. 10270-106; Gibco; Thermo Fisher Scientific, Inc.), $1 \%$ penicillin-streptomycin (cat. no. 15140-122; Gibco; Thermo Fisher Scientific, Inc.) and $1 \%$ sodium pyruvate (cat. no. 11360-039; Gibco; Thermo Fisher Scientific, Inc.). BEAS-2B cells (ECACC 95102433 RRID: CVCL_0168) were grown in BEGM media (cat. no. CC-3170; Lonza) on collagen (cat. no. A1048301; Gibco; Thermo Fisher Scientific, Inc.)-coated tissue culture dishes according to the manufacturer's protocol. NK92 cells (gift from Professor Fathia Mami Chouaib) were cultured in complete RPMI-1640 medium supplemented with 200 IU of IL2 recombinant human protein (cat. no. PHC0021; Gibco; Thermo Fisher Scientific, Inc.). H460 and BEAS-2B were purchased from a commercial source that guarantees cell line authenticity. We tested and confirmed that all the cell lines were mycoplasma-free.

Trypan blue exclusion assay was used to determine the cell number and viability of A549, H460 and BEAS-2B cells exposed to various concentrations and durations of WPSC as described earlier in the text. Subsequently, 50,000 cells (A549 and $\mathrm{H} 460$ ) or 100,000 cells (BEAS-2B) were plated on $3.5-\mathrm{cm}$ dishes for $24 \mathrm{~h}$ after which the cells were treated with $1 \mathrm{ml}$ of complete media containing WPSC at the indicated concentrations. Plates were counted, every day for 7 days and the number of live and dead cells was determined.

RNA extraction/cDNA and $q P C R$. RNA was purified using Easy Blue (cat. no. 17061; Intron Biotechnology, Inc.) according to the manufacturer's protocol. RNA quality and quantity were assessed by nanodrop and $1 \%$ agarose gel electrophoresis. cDNA synthesis was performed using high capacity cDNA reverse transcription kit (cat. no. 4374966; Thermo Fisher Scientific Inc.). qPCR was performed using SYBR-Green (cat. no. 4309155; Thermo Fisher Scientific Inc.) using AB 7500 FAST Real-Time PCR system. Analysis was performed using the $\Delta \Delta \mathrm{Cq}$ method (15). Forward (F) and reverse $(\mathrm{R})$ primers used in this study were: $G A P D H$ forward, (5'-GCCACATCGCTCAGACAC-3') and GAPDH reverse, (5'-CCAGAGTTAAAAGCAGCC-3'); CCL2 forward, (5'-CAGCCAGATGCAATCAATGCC-3') and CCL2 reverse, (5'-TGGAATCCTGAACCCACTTCT-3'), CASP1 forward, (5'-TTTCCGCAAGGTTCGATTTTCA-3') andCASP1 reverse, (5'-GGCATCTGCGCTCTACCATC-3'), IL1B forward, (5'-TTCGACACATGGGATAACGAGG-3') and IL1B reverse, 
(5'-TTTTTGCTGTGAGTCCCGGAG-3'); CD44 forward, (5'-TGCCGCTTTGCAGGTGTATT-3') and CD44 reverse, (5'-CCGATGCTCAGAGCTTTCTCC-3');SERPINE2forward, (5'-TGGTGATGAGATACGGCGTAA-3') and SERPINE2 reverse, (5'-GTTAGCCACTGTCACAATGTCTT-3'); SNAI2 forward, (5'-TAGGAAGAGATCTGCCAGAC-3') and SNAI2 reverse, (5'-CCCCAAGGCACATACTGTTA-3'); ACTA2 forward, (5'-CTATGAGGGCTATGCCTTGCC-3') and ACTA2 reverse, (5'-GCTCAGCAGTAGTAACGAAGGA-3'); IL6 forward, (5'-ACTCACCTCTTCAGAACGAATTG-3') and IL6 reverse, (5'-CCATCTTTGGAAGGTTCAGGTTG-3').

Alkaline comet assay. Cells were harvested and prepared as described in Olive and Banáth (16). Briefly, the treated cells were centrifuged at $100 \mathrm{xg}$ at room temperature for 5 min. Cell pellet was re-suspended in 1X PBS and approximately 5,000 cells per slide were considered for the assay. Cells were mixed with $0.75 \%$ low-melting agarose (LMA) at $37^{\circ} \mathrm{C}$, and the mixture was loaded onto glass slides precoated with $1.5 \%$ normal melting agarose. Coverslips were then placed gently on the slides to allow even spreading of the gel and then placed at $4^{\circ} \mathrm{C}$ for gelling. A third layer of the $0.75 \%$ LMA was added onto the slide to fill any residual holes in the second layer, and was allowed to solidify. After gelling, the slides were immersed in chilled lysing solution containing $2.5 \mathrm{M} \mathrm{NaCl}, 100 \mathrm{mM}$ EDTA, $10 \mathrm{mM}$ Tris base (pH 10) with $1 \%$ Triton $\mathrm{X}-100$ and $10 \%$ DMSO and were kept overnight at $4^{\circ} \mathrm{C}$. After lysis, the slides were placed in a horizontal electrophoresis tank and soaked in cold alkaline electrophoresis buffer (1 mM EDTA, $300 \mathrm{mM} \mathrm{NaOH}$ ). Slides were left for $30 \mathrm{~min}$ for DNA unwinding and electrophoresis was performed at $0.7 \mathrm{~V} / \mathrm{cm}$ and $300 \mathrm{~mA}$ for $35 \mathrm{~min}$. The slides were then removed from the electrophoresis buffer and were neutralized using 0.4 M Tris ( $\mathrm{pH}$ 7.4). To capture images, the slides were stained with $100 \mathrm{ml}$ of ethidium bromide $(0.2 \mathrm{mg} / 100 \mathrm{ml})$ and were visualized at $\times 20$ magnification on Zeiss LSM 800 with Airyscan. In total, 50 images were taken per slide and the data were analyzed using OpenComet (17) pluggin on ImageJ software. The tail length was considered as a suitable parameter for measuring the extent of DNA damage.

Immunofluorescence. Cells were fixed in 4\% paraformaldehyde (cat. no. 28906; Thermo Fisher Scientific Inc.) in 1X PBS for $10 \mathrm{~min}$ at room temperature. Cells were then washed with 1X PBS and permeabilized with 0.1\% TX-100 in PBS for $15 \mathrm{~min}$ at room temperature. Prior to staining, the cells were blocked in 2\% BSA in 1X PBS for $1 \mathrm{~h}$ at room temperature. The cells were then stained with a primary and secondary antibodies as described below with $3 \times 5$ min washes after each antibody staining. Cells were then mounted on glass slides using Prolong gold antifade reagent (cat. no. P36930; Thermo Fisher Scientific, Inc.) and visualized on Zeiss LSM 800 with Airyscan. The comet assays were visualized using a 20x plan apochromat objective, with Zeiss Axio cam 305 mono (Zeiss LSM 800).

Immunological synapse formation assay. For visualizing immunological synapse 100,000 lung cells were incubated with $300,000 \mathrm{NK} 92$ cells in the presence of IL-2 for $30 \mathrm{~min}$ in a $37^{\circ} \mathrm{C}$ incubator. Cells were subsequently fixed and stained for the markers described in the text.

Antibodies used in this study. Mouse monoclonal anti-human Phospho-histone H2AX (cat. no. 05-636; 1:1,000 dilution; Merck Millipore), rabbit anti-human histone H2AX (cat. no. P16104; 1:2,000 dilution; Ray Biotech), rabbit anti-human p21 (cat. no. 2147; 1:1,000 dilution; Cell Signaling Technology), rabbit anti-human 53BP1 (cat. no. 4937; 1:1,000 dilution; Cell Signaling Technology), mouse anti-human p53 (cat. no. 48818; 1:1,000 dilution; Cell Signaling Technology), mouse monoclonal anti-gizzard $\beta$-actin (cat. no. sc-47778; 1:5,000 dilution; Santa Cruz Biotechnology), phalloidin (cat. no. A12379; 1:1,000 dilution; Thermo Fisher Scientific Inc.), DAPI (cat. no. D1306; 1:36,000 dilution; Thermo Fisher Scientific Inc.). Secondary antibodies used are goat anti-mouse Alexa Fluor 568 (A11004; 1:1,000 dilution; Thermo Fisher Scientific, Inc.), goat anti-rabbit Alexa Fluor 488 (cat. no. A11034; 1:1,000 dilution; Thermo Fisher Scientific Inc.), goat anti-mouse Alexa Fluor 488 (cat. no. A11001; 1:1,000 dilution; Thermo Fisher Scientific Inc.), goat anti-rabbit Alexa Fluor 568 (cat. no. A11011; 1:1.000 dilution; Thermo Fisher Scientific Inc.).

Immunoblotting. Cells grown in $3.5-\mathrm{cm}$ plates were washed once with $1 \mathrm{X}$ ice-cold PBS and lysed in $100 \mathrm{ml}$ of RIPA (150 mM NaCl, 0.1\% TX-100, 0.5\% NaDOC, 0.1\% SDS, $50 \mathrm{mM}$ Tris-CL pH 8.0) with protease inhibitor cocktail (cat. no. P2714; Sigma-Aldrich; Merck KGaA). Proteins were quantified following brief sonication by Pierce BCA protein assay kit (cat. no. 23225; Thermo Fisher Scientific Inc.). Then, 8-12 mg of proteins were loaded on 10 or $12 \%$ SDS-PAGE, and transferred onto a nitrocellulose membrane (cat. no. GE10600004; Sigma-Aldrich; Merck KGaA) at $80 \mathrm{~V}$ for $3 \mathrm{~h}$ for low molecular weight proteins or $80 \mathrm{~V}$ for $8 \mathrm{~h}$ for high molecular weight proteins. After incubation with $5 \%$ BSA in TBST (10 mM Tris, pH 8.0, $150 \mathrm{mM} \mathrm{NaCl}, 0.5 \%$ Tween-20) for $60 \mathrm{~min}$ at room temperature, the membrane was washed once with TBST and incubated with the listed antibodies overnight at $4^{\circ} \mathrm{C}$ according to their data sheets.

$\beta$-galactosidase senescence assay. Cells were stained for $\beta$-galactosidase using Senescence $\beta$-galactosidase Staining Kit (cat. no. 9860S; Cell Signaling Technology) according to manufacturer's protocol.

NK92-mediated cytotoxicity assay. Cytotoxicity assay was performed as previously described (18) with the following modifications: IL-2-activated NK92 effector cells were incubated with target $\mathrm{A} 549$ or $\mathrm{H} 460$ cells with the $\mathrm{E} / \mathrm{T}$ ratios, 1:10, and $1: 20$ in a $5 \% \mathrm{CO}_{2}$ incubator at $37^{\circ} \mathrm{C}$ in a 96 -well plate in triplicates. After $6 \mathrm{~h}$ of co-culture, NK activity was measured using the LDH Cytotoxicity Assay Kit (cat. no. 88954; Pierce $^{\mathrm{TM}}$ ) according to the manufacturer's protocol.

Microarray analysis. Total RNA concentrations were determined using the Qubit ${ }^{\circledR}$ RNA HS Assay Kit (cat. no. Q32852; Invitrogen; Thermo Fisher Scientific, Inc.) using Qubit $^{\circledR} 3.0$ (cat. no. Q33216; Invitrogen; Thermo Fisher Scientific, Inc.) and RNA quality was assessed by running a $2 \%$ agarose gel and checking the $18 \mathrm{~S}$ and $28 \mathrm{~S}$ rRNA bands. 
Table I. Major chemical compounds identified in the toluene and ethanol extracts.

Toluene Ethanol

Benzaldehyde

Benzaldehyde, 3-ethoxy-4-hydroxy- (CAS)

Benzene, 1,3-dimethyl-

Benzyl alcohol

Benzenepropanoic acid, 3,5-bis(1,1-dimethylethyl)

-4-hydroxy-, octadecyl ester

Cyclopentane, 1-ethyl-2-methyl-, cis-

Cyclohexane, ethyl-

Decane, 3,3,8-trimethyl-

DECANE, 3,3,7-TRIMETHYL-

Dihydro methyl jasmonate

2,3-Dihydroxypropyl icosanoate, 2TMS derivative

Docosane

Dodecane, 4,6-dimethyl-

Ethylbenzene

Hexadecane, 2,6,10,14-tetramethyl- (CAS)

1-Hexadecanol

Hexane, 3,3-dimethyl- (CAS)
Hexadecane, 2,6,10,14-tetramethyl- (CAS)

Hexadecanoic acid, 1-(hydroxymethyl)-1,2-ethanediyl ester 4H-Pyran-4-one, 2,3-dihydro-3,5-dihydroxy-6-methyl-

5-Hydroxymethylfurfural

1H-Indene, 1-hexadecyl-2,3-dihydro-

Nonyl tetradecyl ether

Nicotine

octadecanoic acid, 3-oxo-, ethyl ester

Octadecanoic acid, 2,3-dihydroxypropyl ester

Phenol, 2,4-bis(1,1-dimethylethyl)-, phosphite (3:1)

Pyrrolidine-D4

Ethanol, 2-[(triethylsilyl)oxy]-

1,2,3-Propanetriol, 1-acetate

Pyridine, 3-(1-methyl-2-pyrrolidinyl)-, (S)- (CAS)

Propanal, 3-ethoxy- (CAS)

Trans-Anethole

Tris(2,4-di-tert-butylphenyl) phosphate

Trans-4-hydroxymethyl-2-methyl-1,3-dioxolane
Subsequently, $100 \mathrm{ng}$ of good quality RNA was prepared for transcriptome profiling using the Human Clariom ${ }^{\mathrm{TM}} \mathrm{D}$ Assay (cat. no. 902922; Applied Biosystems). All steps were performed following the manufacturer's protocol, where in brief, the GeneChip ${ }^{\text {TM }}$ WT PLUS Reagent Kit (cat.no. 902281; Applied Biosystems) was first used to generate amplified and biotinylated sense-strand DNA that was then hybridized on the Human Clariom ${ }^{\mathrm{TM}}$ D Arrays (Applied Biosystems ${ }^{\mathrm{TM}}$ ). These arrays include over $6,765,500$ probes that can detect genes, exons, and alternative splicing events giving rise to coding and long non-coding RNA isoforms. The arrays were washed and stained on the GeneChip Fluidics Station 450 (cat. no. 00-0079; Applied Biosystems) and scanned with the GeneChip ${ }^{\mathrm{TM}}$ Scanner 3,000 7G (cat. no. 00-0213; Applied Biosystems). The scanned images and DAT files were inspected for the absence of bubbles and proper scanner alignment, respectively, while the generated raw files (CELL) were imported to the Transcriptome Analysis Console (TAC) 4.0 software (Applied Biosystems) for data analysis. Expression (Gene + Exon) analysis was carried out on TAC by applying the Gene + Exon-Signal Space Transformation-Robust Multi-Array Average (SST-RMA) algorithm. Default settings were used for determining relative gene expression levels of each transcript, which included applying the ebayes (Empirical Bayes Statistics for Differential Expression) ANOVA method for statistical testing, as well as setting the threshold for gene expression fold change (FC) between the treated and untreated samples at $\leq-2$ or $\geq 2$. Only coding and multiple complex loci with P-value $<0.05$ were considered for further analysis. A heatmap was generated by hierarchical clustering of common deregulated genes using complete linkage with Euclidean distance on Heatmapper (19). Venn diagram was plotted using Venny (20). Pathway enrichment analysis was performed using Gene Set Enrichment Analysis (GSEA) software (21), wherein overlaps between common deregulated genes in the microarray data and Hallmark gene sets $\mathrm{H}$ were computed (22). Pathways with P-value $<0.05$ and FDR q-value $<0.05$ were considered significantly enriched.

Statistical analysis. Statistical analyses were carried out using GraphPad Software version 6 (GraphPad Software, Inc.). All data are expressed as means \pm SEM. Significant differences were found using two-way analysis of variance (ANOVA) followed by Bonferroni post hoc test.

\section{Results}

Toxic compounds identified in WPSC. We first attempted to identify chemical compounds in WPSC by analyzing the toluene extract and the ethanol solution using GCMS. Many peaks were identified in the chromatograms including some that are present at trace levels. Major peaks are shown in Fig. 1. An internal standard was used to evaluate the reproducibility of the analysis and to allow the calculation of relative concentrations. Table I summarizes the major chemical compounds identified in both the toluene and ethanol solutions. Most of these compounds are known to cause serious health problems. The safety, hazard and toxicity evaluation of the toluene and ethanol extracts were performed using ToxNet and PubChem resources. Several compounds were identified as carcinogens or may cause various toxicities and health hazards. Several harmful compounds were identified and may be associated with the burning of coal as reported in a previous study (14). For example, ethyl benzene, a component previously identified in coal smoke was also 


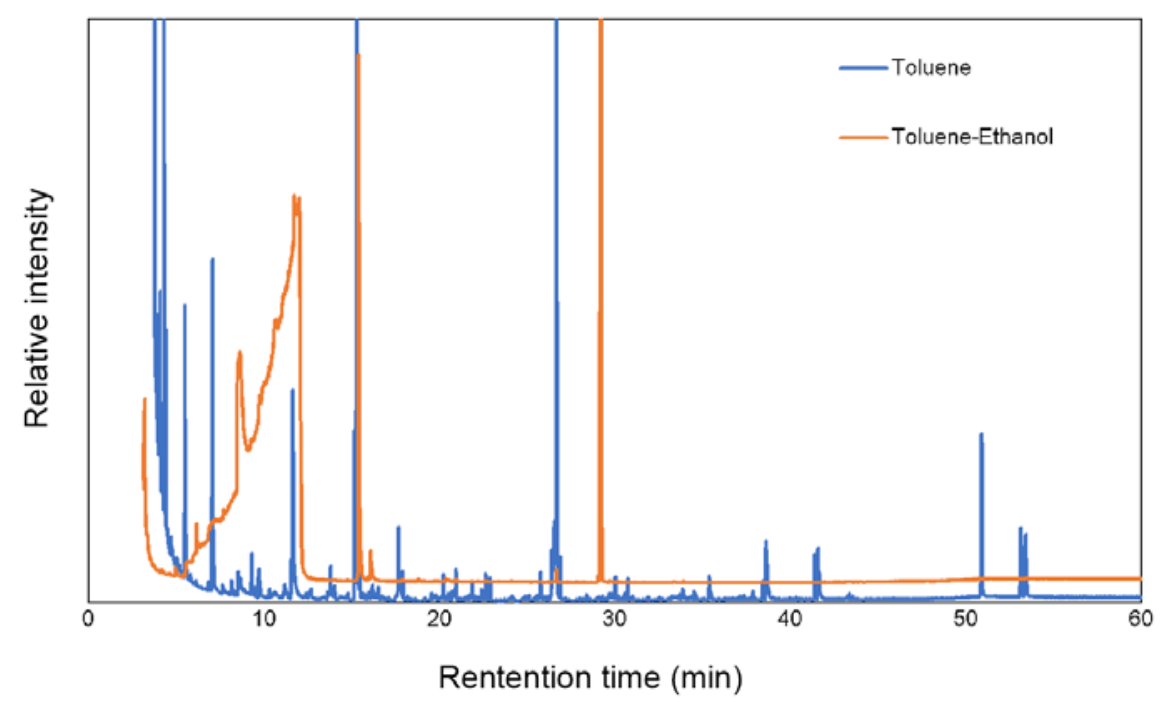

Figure 1. GCMS chromatograms for WPSC. For this step, $2 \mathrm{ml}$ of toluene was added to the smoke condensate ( $20 \mathrm{ml})$, agitated for $2 \mathrm{~h}$ at room temperature on an orbital shaker (Z206A), and spun at $100 \mathrm{x}$ g for $5 \mathrm{~min}$ at room temperature. The toluene was then separated prior to dissolving in $2 \mathrm{ml}$ ethanol which was used for the GCMS analysis. Toluene extraction is shown in blue; ethanol extraction is shown in orange.

A

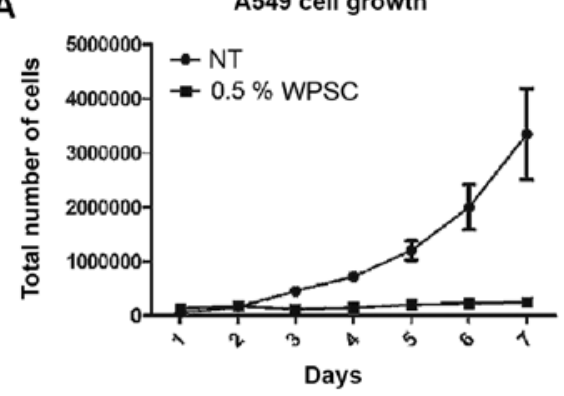

C

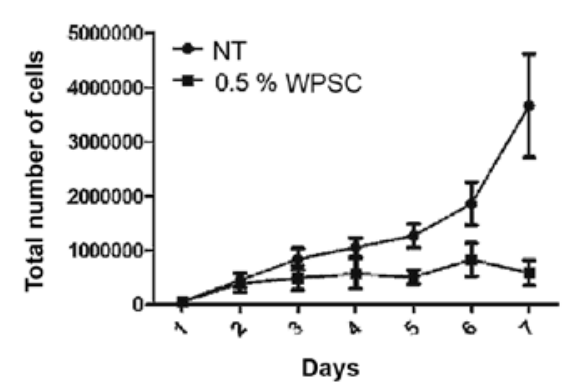

E

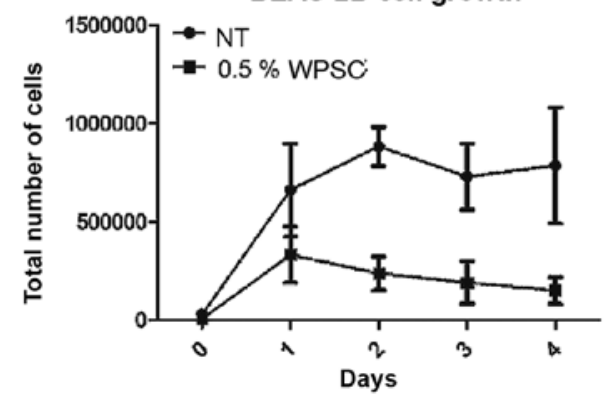

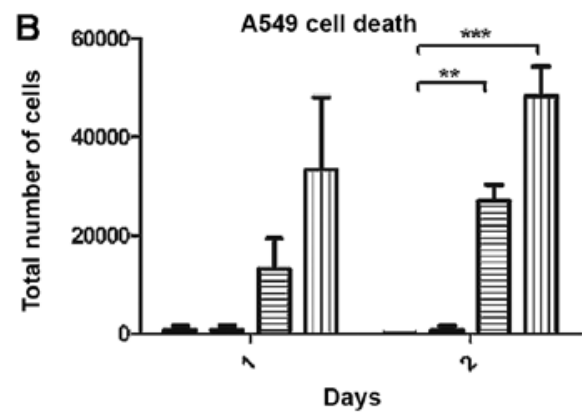

D

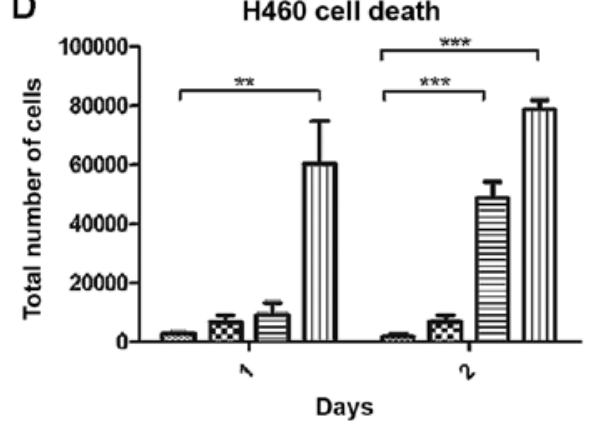

$\mathbf{F}$

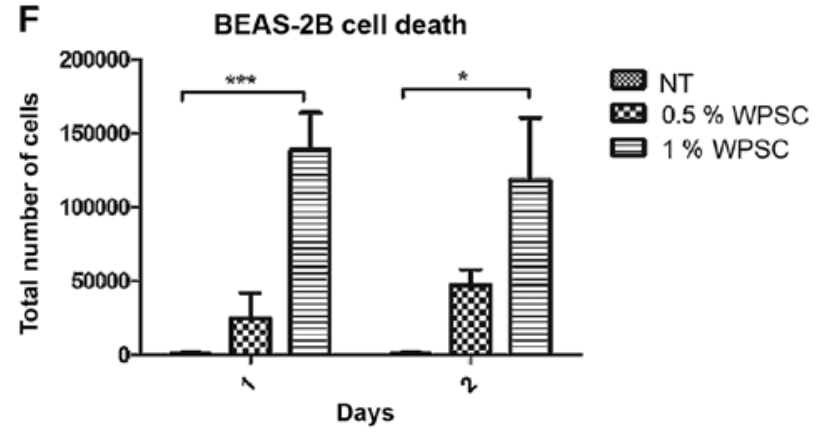

Figure 2. WPSC effects on lung cell proliferation. Growth curves for A549, H460 and BEAS-2B cell lines grown in the presence of 0.5\% WPSC are shown. The cell number was determined by counting in a hemocytometer after detachment of cells with trypsin every day up to 8 days. The number of live cells is shown in A, C and E. The number of dead cells is shown in B, D and F. Results represent means of three independent experiments, were run in duplicates and data represent mean \pm standard error of mean. ${ }^{*} \mathrm{P} \leq 0.05,{ }^{* *} \mathrm{P} \leq 0.01$ and ${ }^{* * *} \mathrm{P} \leq 0.001$. 
A

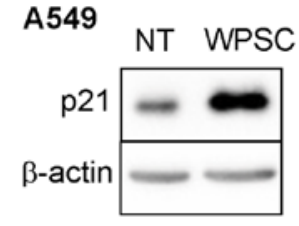

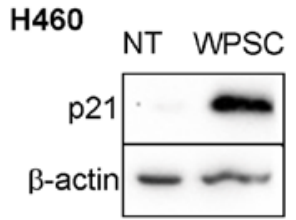

B

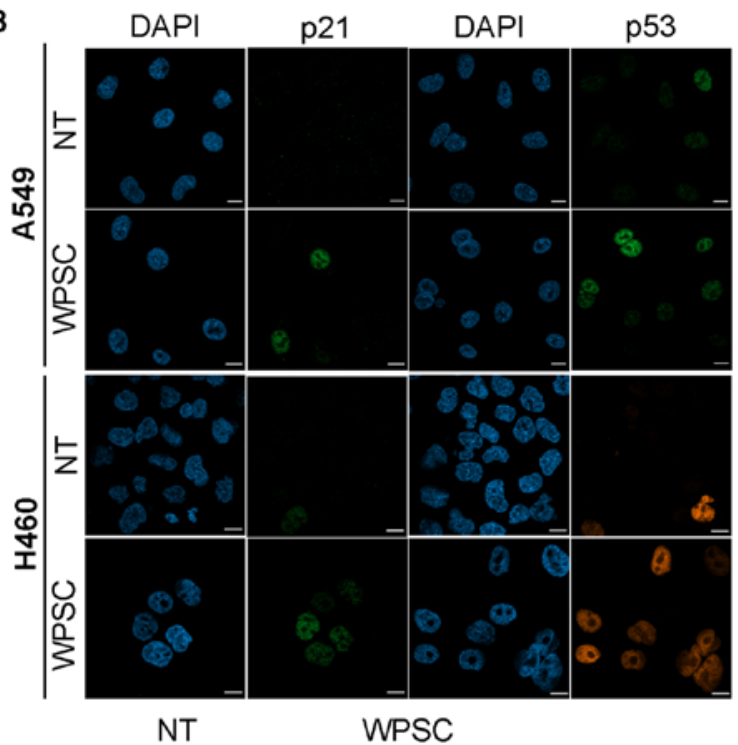

C

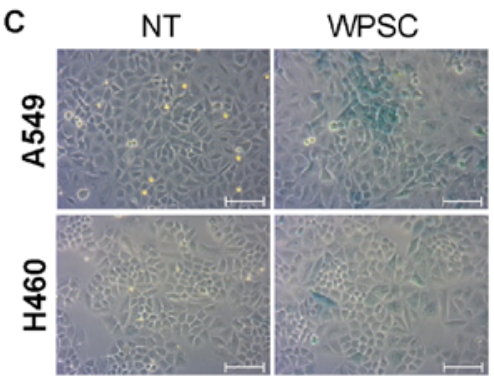

D

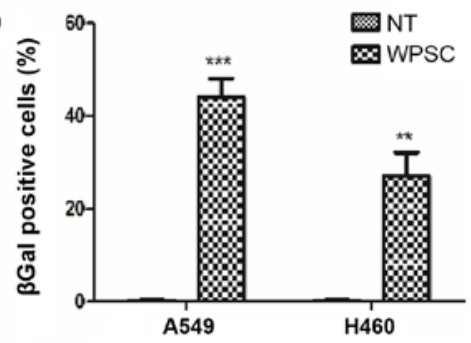

Figure 3. Analysis of the effect of WPSC on cellular senescence and apoptosis in lung cancer cells. A549 and H460 cell lines were treated with 0.5\% WPSC for 8 days. (A) Western blotting was performed by standard procedures with anti-p21 antibodies. $\beta$-actin was used as a loading control. (B) Representative images of confocal microscopic analysis of p21 (green) and p53 (green for A549 and orange for H460) in WPSC-treated cells. Scale bar, $10 \mu$ m. (C) WPSC-treated cells were stained for SA- $\beta$-galactosidase activity. Cell morphology was photographed under phase-contrast microscope. Scale bar, $100 \mu \mathrm{m}$. (D) Percentage of $\beta$-galactosidase-positive cells was quantified by counting 100 cells. Results are the means of three independent experiments. ${ }^{* *} \mathrm{P} \leq 0.01$ and ${ }^{* * * *} \mathrm{P} \leq 0.001$.

found in WPSC. It is classified by the International Agency for Research on Cancer (IARC) as a possible human carcinogen and may cause kidney failure as a result of prolonged exposure at low concentrations (14). Indene, another compound found in WPSC, is a polycyclic aromatic hydrocarbon which was identified in coal smoke (14). Furthermore, several identified compounds are known to cause irritation to the skin, eyes and respiratory tract, including 3-ethoxy-4-hydroxy-benzaldehyde, 1,3-dimethyl-benzene, benzyl alcohol, docosane, ethylbenzene, 3-ethoxypropionaldehyde, and 2,3-dihydro-3,5dihydroxy-6-methyl-4H-pyran-4-one. Many of the identified compounds are known to interfere with and alter the functions of the central nervous system including 1,3-dimethyl benzene, benzyl alcohol, ethyl cyclohexane, ethyl benzene and nicotine. In addition, several compounds are known to induce DNA damage including benzaldehyde, 1,3-dimethyl Benzene, and 5-hydroxymethyl furfural (23).

Effect of WPSC on lung cancer cell proliferation. We first tested the cytotoxic effect of WPSC on two non-small cell lung cancer cells, A549, and H460 as well as on a normal bronchial epithelial cell line, BEAS-2B. Both cell number and viability of tested cells were measured in the presence of various concentrations of WPSC condensate $(0.5,1$ and $2 \%$ ) for 8 consecutive days with re-administration of fresh WPSC at day 4. Additionally, WPSC treatment resulted in a dose- and time-dependent decrease in cancer cell proliferation (Fig. 2A-D). Hemocytometer images are shown in Fig. S1. At higher doses of 1 and 2\% an increase in cell death was observed. By contrast, the lowest concentration of $0.5 \%$ resulted in a significant increase in the cell death of BEAS-2B normal lung cells following 2 days of treatment (Fig. 2E and F); consequently, these cells were not analyzed further. Subsequent experiments on lung cancer cells were performed using $0.5 \%$ WPSC, considering the absence of cell death.

WPSC increases DNA damage and cellular senescence in lung cancer cells. DNA damage often arises as a result of normal cellular processes, as a by-product of the cell's own metabolic activity. It can also be induced as a result of environmental exposure to chemical agents. We therefore investigated whether WPSC induced DNA damage and used the alkaline comet assay to detect and quantify the degree of gross DNA damage. As shown in Fig. S2A and $\mathrm{B}$, WPSC induced an increase in tail length in the cancer cell lines A549 and H460 when compared to untreated cells, indicating an increase in the frequency of DNA breaks. Comet assay reflects the physical status of genomic DNA while $53 \mathrm{BP} 1 / \gamma \mathrm{H} 2 \mathrm{AX}$ staining represents processes related to the biological DNA damage response (DDR) (24). We investigated the effect of WPSC on the DDR using two markers: Phosphorylated histone H2AX at Ser139 $(\gamma \mathrm{H} 2 \mathrm{AX})$ and 53BP1. Foci formation indicates the aggregation of these proteins induced by DNA damage. Consistent with the comet tail formation, in response to WPSC treatment, an increase 
A

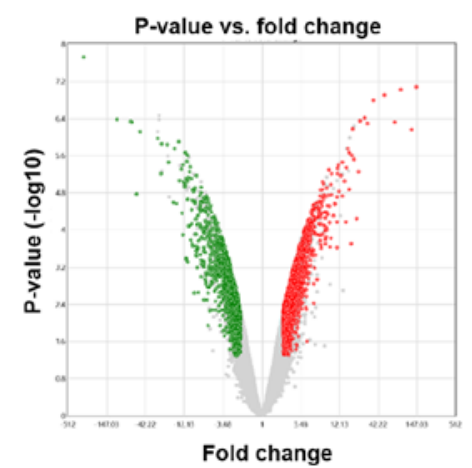

C

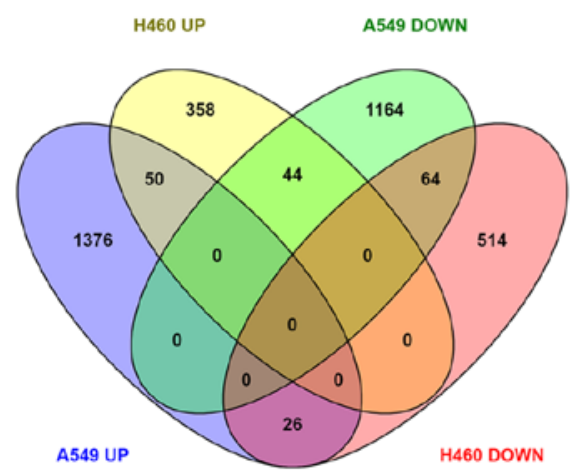

$\mathrm{H} 460$

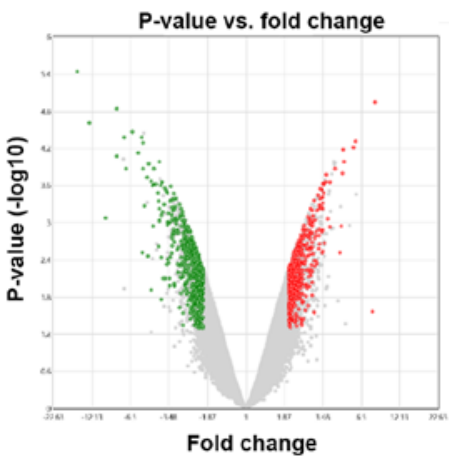

B

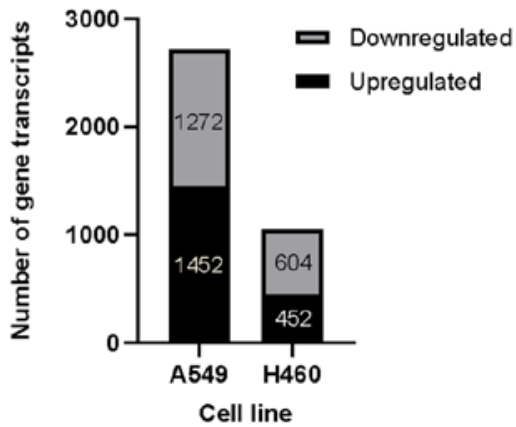

E

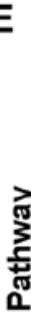

D

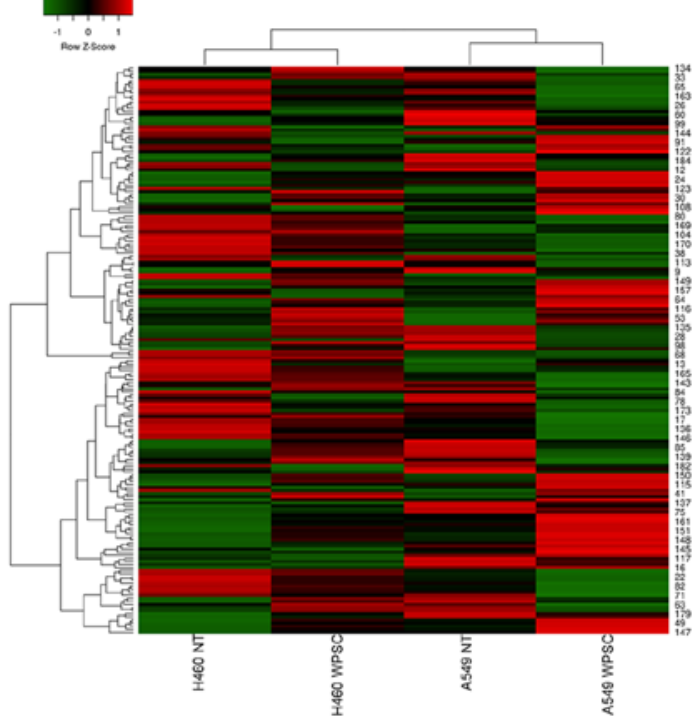

P-value $<0.05$

FDR q-values $<0.05$

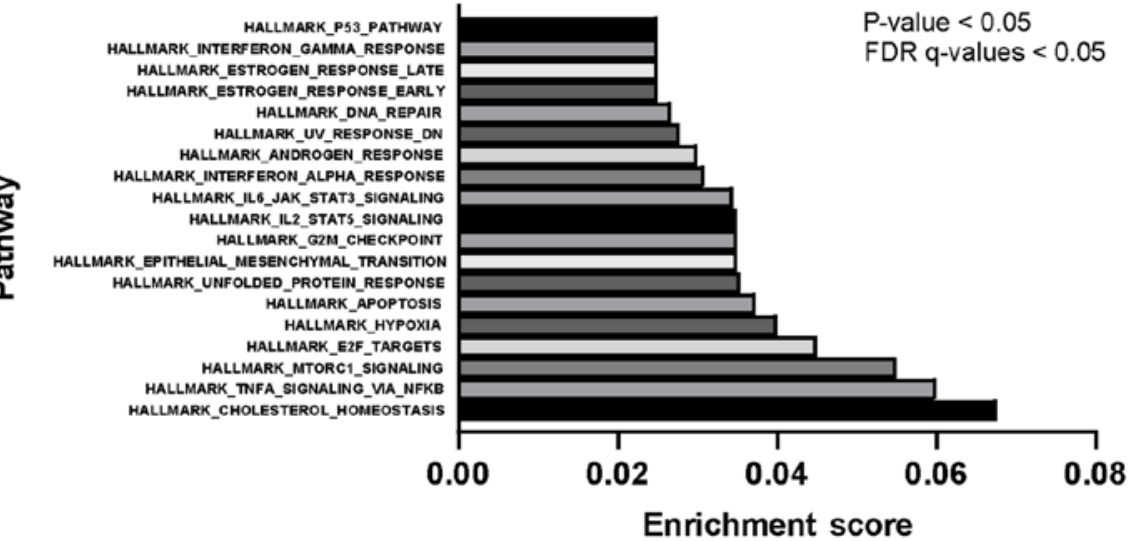

Figure 4. Differentially expressed genes and pathway analysis based on microarray data of A549 and H460 cells were treated with $0.5 \%$ WPSC for 8 days. (A) Volcano plots of differentially expressed gene transcripts. P-values(-log10) were plotted against the fold change. Green dots are the downregulated gene transcripts and red dots are the upregulated gene transcripts. Grey represents the filtered-out transcripts. (B) Bar graph of the number of upregulated and downregulated gene transcripts in each cell line. (C) Venn diagram of the overlap between the A549 up- and downregulated gene transcripts with those of H460. (D) Heatmap of the 184 commonly deregulated gene transcripts in non-treated (NT) and waterpipe smoke condensate (WPSC)-treated A549 and H460 cells. The rows represent $\log 2$ expression levels of each gene in the four conditions, which are fitted using a z-score ranging between -1 and 1 , and clustered based on complete linkage with Euclidean distance. (E) Pathway analysis of the 184 gene transcripts in the Gene Set Enrichment Analysis (GSEA)-Hallmark gene sets. Pathways with P-value $<0.05$ and FDR (false discovery rate) q-values $<0.05$ are plotted against the enrichment score. Enrichment score is the number of genes in our dataset belonging to a pathway divided by the total number of genes in that pathway. The higher the score, the more enriched the pathway. (A-E) Analysis carried out considering only gene transcripts of coding genes and multiple complex genes with P-value $<0.05$ and fold change of $\leq-2$ or $\geq 2$.

in the nuclear foci for both $\gamma \mathrm{H} 2 \mathrm{AX}$ and 53BP1 in A549 and H460 cells was observed (Fig. S2C-E).

Since waterpipe smoke condensate resulted in decreased cell growth, we tested whether the lung cancer cells were undergoing apoptosis or cell cycle arrest and senescence.
Consistent with cell cycle arrest and induction of senescence, we found that WPSC induced an increase in p21 protein expression as revealed by western blot analysis (Fig. 3A). Using confocal microscopy analysis, we demonstrated an accumulation of both p21 and p53 proteins in the nuclei of 

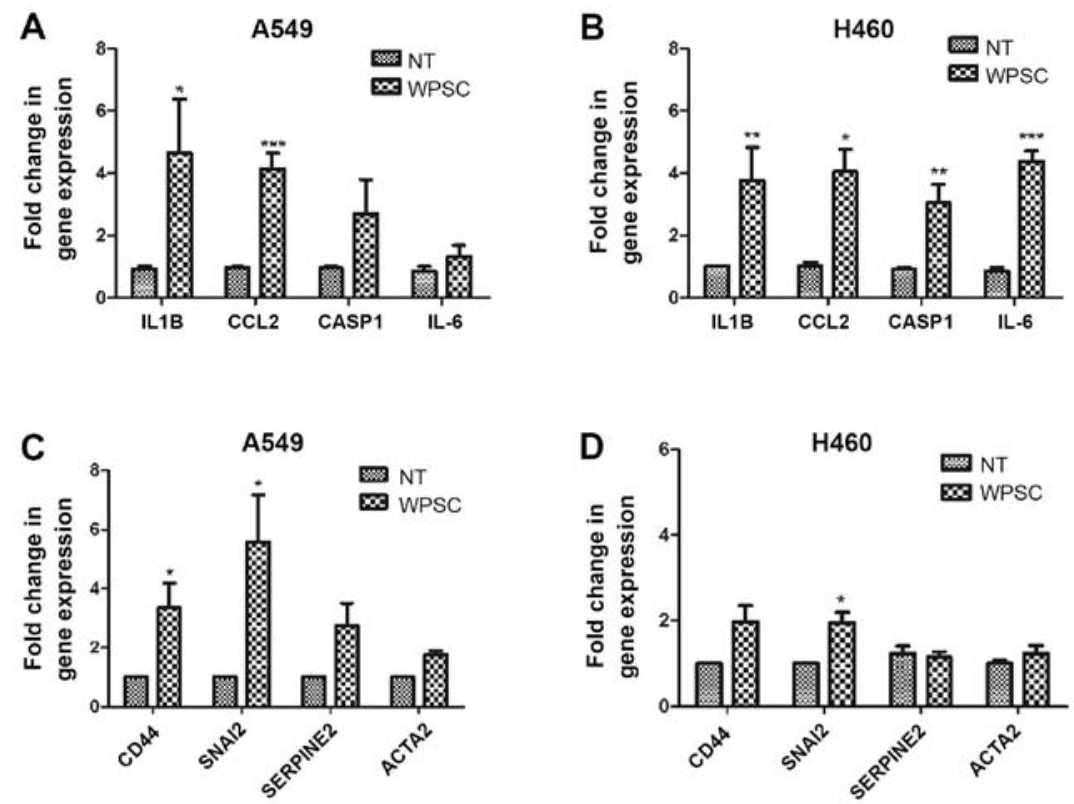

E
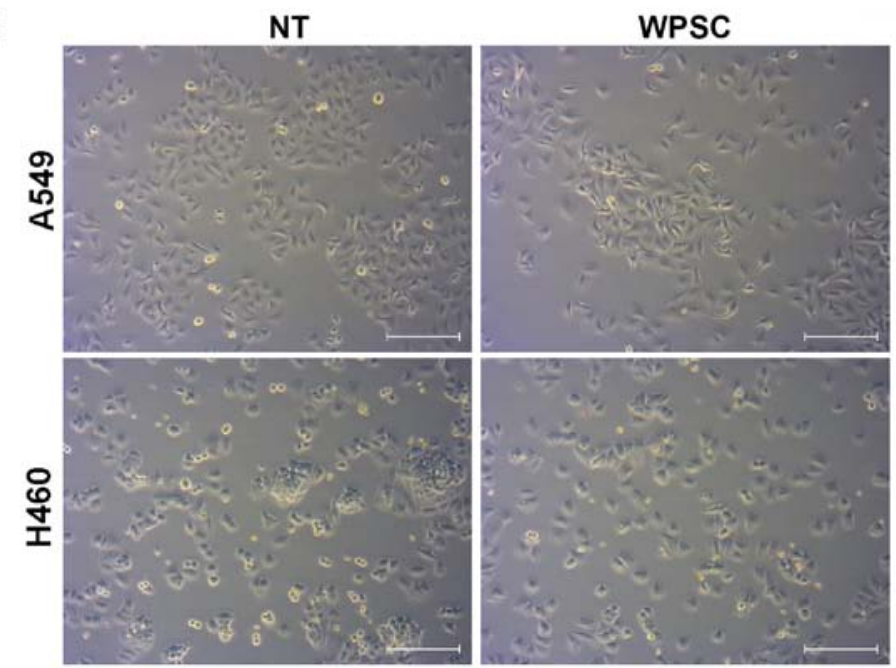

Figure 5. WPSC effects on the inflammatory response and on the expression of EMT- and stemness-related genes. (A and C) A549 and (B and D) H460 gene expression was analyzed by qPCR for caspase-1, IL-1 3 , CCL2, IL-6, CD44, SNAI2, SERPINE2 and ACTA2. Results represent means of three independent experiments, and were run in duplicates. ${ }^{*} \mathrm{P} \leq 0.05,{ }^{* *} \mathrm{P} \leq 0.01,{ }^{* * *} \mathrm{P} \leq 0.001$. (E) Bright-field images for the A549 and H460 cells cultured with WPSC. Scale bar, $100 \mu \mathrm{m}$.

both cancer cells (Fig. 3B). This was also supported by an increase in $\beta$-galactosidase activity in these cells indicating the induction of cellular senescence (Fig. 3C and D).

Transcriptomic changes associated with WPSC treatment. To determine whether WPSC treatment impacts the molecular pathways associated with EMT, stemness and immune evasion and to identify novel gene expression patterns in response to WPSC treatment, a microarray analysis was performed. RNA derived from biological duplicates of A549 and H460 cell lines 8 days post-treatment with WPSC, as well as their untreated counterparts was analyzed. Considering only coding and multiple complex loci with fold change of $\leq-2$ and $\geq 2$ and P-value of $<0.05$, volcano plots were generated. A greater number of differentially expressed gene transcripts in A549 (1452 upregulated and 1272 downregulated) in comparison with H460 (452 upregulated and 604 downregulated)
(Fig. 4A and B) was observed. Among these differentially expressed transcripts, 184 were common to both A549 and H460 (Fig. 4C and D). Of these 70 transcripts showed opposite patterns of deregulation: upregulated in one cell line and downregulated in the other or vice versa. Additionally, 50 transcripts were upregulated, and 64 transcripts were downregulated in the two cell lines, respectively (Fig 4D). Pathway enrichment analysis revealed that the commonly deregulated genes clustered in pathways involved EMT, the cell cycle, apoptosis, DNA repair and the inflammatory response, among others (Fig. 4E).

WPSC activates the inflammatory response in lung cancer cells. Waterpipe smoking has been shown to trigger the inflammatory response in humans as measured in the blood of waterpipe smokers (25). Using microarray analysis, gene expression in the inflammatory pathway (Fig. 5A and B) 

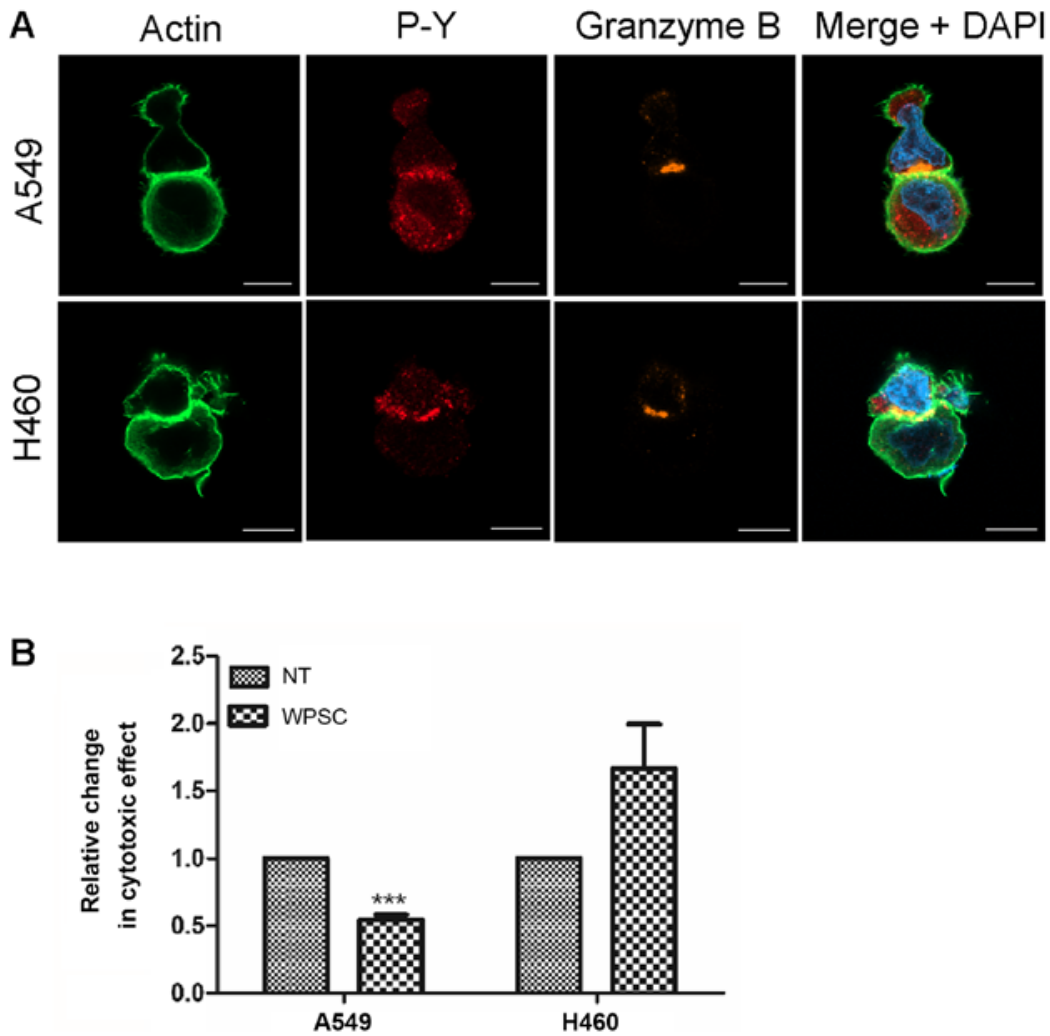

Figure 6. WPSC effects on NK-cell synapse formation and NK-mediated cytotoxicity. A549 and H460 cells were treated with $0.5 \%$ WPSC for 8 days. (A) Cells were incubated with NK92, fixed, and stained for immune synapse markers. Representative confocal images show cells stained for F-actin (phalloidin green), phospho-tyrosine (red), Granzyme-B (orange) and DAPI (blue). Scale bar, $10 \mu \mathrm{m}$. (B) Cytotoxic effects of NK cells was measured after $6 \mathrm{~h}$ of co-culture with WPSC-treated A549 and H460. Results represent means of three independent experiments, run in triplicates. ${ }^{* * *} \mathrm{P} \leq 0.001$.

was detected. IL-1 $\beta$ is a key mediator of inflammation and promotes invasiveness (26), whereas the chemokine CCL2 regulates inflammatory responses and also plays a role in tumor progression and metastasis (27). In addition, IL-6 is a pro-inflammatory cytokine with key roles in EMT (28). Fig. 5A and B shows a significant increase in expression levels of these genes in response to WPSC. We also investigated the expression levels of caspase-1, the cysteine protease that converts the inactive proform of IL-1 $\beta$ to the active inflammatory cytokine (29). The results showed that the expression level was slightly increased in the two cells (Fig. 5A and B), consistent with the increase in IL-1 $1 \beta$.

WPSC induces EMT and stemness properties. EMT and stem cell-like traits are intertwined processes that dictate tumor aggressiveness. It is well established that EMT generates cells with stem cell properties (30). Using microarray analysis, several genes involved in EMT were found to be enriched including $I L-6, I L-15$, GLIPRI, CD44 and COL5A. Using qPCR analysis, we demonstrated that both EMT and stemness genes are regulated (Fig. 5C and D), an increase in the cancer stem cell marker CD44 was observed. CD44 is also known to promote EMT (31). Furthermore, an increase in SNAI2, an EMT key transcription factor (32), SERPINE2, a protease that promotes ECM deposition and invasion (33) and ACTA2 coding for alpha smooth muscle actin that promotes motility and invasion (34) were also increased in A549 cells. Cell morphological changes in response to WPSC were observed. WPSC treatment converted the cells from a 'cuboidal' epithelial structure into an elongated mesenchymal shape (Fig. 5E).

WPSC effect on synapse formation and NK cell-mediated killing. We examined whether WPSC treatment of cancer cells interferes with tumor cell recognition and killing. As is evident in Fig. 6A, the immunological synapse between NK cells and WPSC-treated A549 and H460 cancer cell was not affected. Nevertheless, as shown in Fig. 6B, WPSC induced a significant decrease in the killing of A549 cells but had no significant effect on the $\mathrm{H} 460$ cells.

\section{Discussion}

In the present study, we investigated the effects of WPSC, using a new method based on a smoking topography stimulating machine on non-small-cell lung cancer cells. We demonstrated that WPSC treatment resulted in a dose-dependent decrease in cell proliferation with cell death at higher concentrations. Both cellular senescence and apoptosis were induced in cancer cells at the lower WPSC concentration of $0.5 \%$. However, such treatment resulted in cell death of normal lung cells. As such, we are in the process of addressing the effects of short-term duration treatment with various concentrations of WPSC on normal lung cells. Furthermore, we did not explore doses lower than $0.5 \%$ as this did not inhibit growth in cancer cells. However, the molecular changes described in this study may be induced at lower doses. Adaptive cellular responses are activated upon microenvironmental stress, such as WPS 
exposure, and are critical in the prevention of tissue damage and transformation. The net effect of these responses depends on the duration, nature, and intensity of the stress. Indeed, at shorter duration treatment of $72 \mathrm{~h}$ we did not observe any cell death (data not shown), which is consistent with previous findings showing that only senescence was generated at this time point in A549 cells (10).

Prolonged exposure to environmental stresses may become deleterious in promoting cell death, excessive inflammation, and tissue remodeling. Indeed, we observed that WPSC treatment resulted in increased DNA damage and a subsequent increase in $\gamma \mathrm{H} 2 \mathrm{AX}$ and 53BP1, which is consistent with the recent finding of Yoshida et al, indicating that tobacco smoking resulted in the increase in mutational burden of lung cells (35), and with a known increase in the expression of both $\gamma \mathrm{H} 2 \mathrm{Ax}$ and 53BP1 in several cancers including breast, bladder, lung, head and neck (36). By contrast, cigarette smoke has been shown to induce a decrease in nucleotide excision repair mechanisms, and does induce DNA damage as measured by COMET assay $(37,38)$, which raises the interesting possibility that other factors present in WPS may induce a toxic response independent of DNA damage in these cells.

We then analyzed the effects of 8-day treatment of WPSC on the transcriptomic profile of A549 and H460 cells. The results showed an increase in the expression of genes involved in inflammation, EMT and in the generation of cancer stem cells. It is well known that inflammation plays an important role in the tumor-specific microenvironment, which is thought to facilitate all phases of tumorigenesis, from initiation to metastasis (39). Inflammatory mediators also exhibit the potential to induce the acquisition of CSCs properties (40). In the course of this study, we demonstrated an increase in IL-1 $\beta$, IL-6, CCL2 and caspase-1 levels, known to be associated with the induction of EMT (41-43). IL- 6 and IL-1 $\beta$ are also found to be senescence-associated secreted factors (44). WPS in humans has a significant association with systemic inflammation $(25,45,46)$. Our results are consistent with this role for WPSC and further highlight the importance of inhibiting inflammatory processes in WP smokers as a means for more effective cancer treatment.

Of the EMT-related genes, we observed an increase in the expression of SNAI2, SERPINE2, ACTA2 as well as CD44, also is a regulator of cancer stemness. WPS was shown to induce EMT in breast cancer cell lines through FAK and Erk1/Erk2 expression (47) and resulted in an increase in invasion and migration properties of breast cancer cells (48). Our results therefore suggest that WPSC exposure to lung cancer cells may change their physiology to promote EMT processes and acquire CSCs properties.

NK cell-mediated immune surveillance strengthens host defense against certain microbial agents and cells undergoing malignant transformation. We investigated the effects of this WPS treatment on the ability of NK cells to recognize and kill the lung cancer cell targets. To date, no data are available as to the effect of WPS on NK cell function. Nevertheless, in mice, chronic exposure to WPS has been reported to promote immune suppression (49). In addition, in cigarette smokers lower populations of NK cells are found (50), and patients with lung cancer had a marked decrease in NK activity compared to non-smokers (51). However, other reports indicate that cigarette smoking was associated with an increase in NK cell tumoricidal activity without any alteration in the absolute number of NK cells in blood (52). Furthermore, NK cells from cigarette-exposed mice produced more IFN- $\gamma$ following stimulation with IL-12, IL-18, or both (53). Under our experimental conditions, the results showed that A549 cell killing was reduced as compared to non-treated cells, whereas $\mathrm{H} 460$ cell survival was not affected. However, the capacity of the NK cells to form synapses with the WPSC-treated cancer cells was not affected in the two cell lines. This is most likely due to genetic variations in the two cell lines, engaging communication networks that could also include the release of inflammatory mediators that signal to the immune system. This is interesting as one possibility is that WPSC could induce several pathways that affect susceptibility to lysis. Nevertheless, we did not observe a correlation between the EMT/CSC induction in A549 cells and a decrease in their NK-mediated cell lysis.

As a limitation of the study, we did not explore the molecular mechanisms of cell apoptosis, as we found WPSC affecting other hallmark properties of cancer including EMT-, stemness- and genomic instability (DNA damage)-related changes. These characteristics are not unique to waterpipe smoke as cigarette smoke has also been shown to induce EMT cell properties (54) in addition to apoptosis (55).

WPSC can induce apoptosis (12). At the same time, WPSC also drives hallmark cancer properties (senescence and EMT, stemness and genomic instability) that promote survival of these cells. In addition, these cells also acquire properties to escape immune surveillance, which complicates the situation further. These characteristics are not unique to WPS as cigarette smoke has also been shown to impair NK- mediated immune surveillance (54) and to induce EMT cell properties (54) as well as apoptosis (55). We are currently culturing the cells in WPSC media for longer durations (up to 4-5 months) and we see that these tumor cells keep dividing (unpublished data). As DNA damage contributes to increased genomic instability and mutational burden, WPSC can also contribute to genetic heterogeneity of tumors.

Our results indicate that WPSC is a contributing factor in the pathogenesis of lung cancer, through impairing cell growth, inducing inflammation and DNA damage. If we are to assume that a cancer patient continues to smoke, WPSC may serve as fuel to the cancer cells and may contribute to metastases. In fact, continued smoking is considered a strong adverse predictor of survival and increases the risk of a second lung cancer compared to those patients who stopped smoking (56). Thus, therapy modalities can be more effective by eliminating smoke exposure to cancer patients and by targeting the inflammatory mechanisms in order to control the emergence of aggressive cancer clones with EMT/CSCs features.

\section{Acknowledgements}

The authors would like to convey appreciation to Angele Fauvel, to Abderemane Abdou (INSERM U1186) and to Ziad Sara (AUS), for their technical assistance. 


\section{Funding}

The present study was supported by Al Jalila Foundation (AJF 2018009) to Zaarour. The smoke sampling and analysis research were funded by the office of Research and Graduate Studies at the American University of Sharjah (FRG19-L-S11).

\section{Availability of data and materials}

The datasets used and/or analyzed during the current study are available with the corresponding author on reasonable request.

\section{Authors' contributions}

SC conceived, significantly guided in the design, analysis, and interpretation of the findings of this study. RFZ, PP, NZ, AR and ST conceived and designed experiments, acquired and interpreted data. RAK, FA performed the microarray-related experiments and analysis with contributions from GHV. YES performed the WPSC purification and analysis. HN conducted the confocal imaging. All authors discussed the results and contributed to the final manuscript.

\section{Ethical approval and consent to participate}

Not applicable.

\section{Patient consent for publication}

Not applicable.

\section{Competing interests}

All authors declare that they have no competing interests.

\section{References}

1. Polverino F, Sam A and Guerra S: COPD: To Be or Not to Be, That is the Question. Am J Med 132: 1271-1278, 2019.

2. Montazeri Z, Nyiraneza C, El-Katerji H and Little J: Waterpipe smoking and cancer: Systematic review and meta-analysis. Tob Control 26: 92-97, 2017.

3. Talhout R, Schulz T, Florek E, van Benthem J, Wester P and Opperhuizen A: Hazardous compounds in tobacco smoke. Int J Environ Res Public Health 8: 613-628, 2011.

4. Shihadeh A, Schubert J, Klaiany J, El Sabban M, Luch A and Saliba NA: Toxicant content, physical properties and biological activity of waterpipe tobacco smoke and its tobacco-free alternatives. Tob Control 24 (Suppl 1): i22-i30, 2015.

5. Maziak W, Jawad M, Jawad S, Ward KD, Eissenberg T and Asfar T: Interventions for waterpipe smoking cessation. Cochrane Database Syst Rev (7): CD005549, 2015.

6. Etemadi A, Poustchi H, Chang CM, Blount BC, Calafat AM, Wang L, De Jesus VR, Pourshams A, Shakeri R, Shiels MS et al: Urinary biomarkers of carcinogenic exposure among cigarette, waterpipe, and smokeless tobacco users and never users of tobacco in the Golestan Cohort Study. Cancer Epidemiol Biomarkers Prev 28: 337-347, 2019.

7. Boskabady MH, Farhang L, Mahmodinia M, Boskabady M and Heydari GR: Comparison of pulmonary function and respiratory symptoms in water pipe and cigarette smokers. Respirology 17: 950-956, 2012.

8. Awan KH, Siddiqi K, Patil Sh and Hussain QA: Assessing the affect of waterpipe smoking on cancer outcome - a systematic review of current evidence. Asian Pac J Cancer Prev 18: 495-502, 2017.
9. Alsaad AM, Al-Arifi MN, Maayah ZH, Attafi IM, Alanazi FE, Belali OM, Alhoshani A, Asiri YA and Korashy HM: Genotoxic impact of long-term cigarette and waterpipe smoking on DNA damage and oxidative stress in healthy subjects. Toxicol Mech Methods 29: 119-127, 2019.

10. Rammah M, Dandachi F, Salman R, Shihadeh A and El-Sabban M: In vitro cytotoxicity and mutagenicity of mainstream waterpipe smoke and its functional consequences on alveolar type II derived cells. Toxicol Lett 211: 220-231, 2012.

11. Bodas M, Van Westphal C, Carpenter-Thompson R, K Mohanty D and Vij N: Nicotine exposure induces bronchial epithelial cell apoptosis and senescence via ROS mediated autophagy-impairment. Free Radic Biol Med 97: 441-453, 2016.

12. Rammah M, Dandachi F, Salman R, Shihadeh A and El-Sabban M: In vitro effects of waterpipe smoke condensate on endothelial cell function: A potential risk factor for vascular disease. Toxicol Lett 219: 133-142, 2013.

13. Gerlinger M, Rowan AJ, Horswell S, Math M, Larkin J, Endesfelder D, Gronroos E, Martinez P, Matthews N, Stewart A, et al: Intratumor heterogeneity and branched evolution revealed by multiregion sequencing. N Engl J Med 366: 883-892, 2012.

14. Elsayed Y, Dalibalta S and Abu-Farha N: Chemical analysis and potential health risks of hookah charcoal. Sci Total Environ 569-570: 262-268, 2016.

15. Livak KJ and Schmittgen TD: Analysis of relative gene expression data using real-time quantitative PCR and the 2(-Delta Delta C(T)) Method. Methods 25: 402-408, 2001.

16. Olive PL and Banáth JP: The comet assay: A method to measure DNA damage in individual cells. Nat Protoc 1: 23-29, 2006.

17. Gyori BM, Venkatachalam G, Thiagarajan PS, Hsu D and Clement MV: OpenComet: An automated tool for comet assay image analysis. Redox Biol 2: 457-465, 2014.

18. Terry S, Abdou A, Engelsen AST, Buart S, Dessen P, Corgnac S, Collares D, Meurice G, Gausdal G, Baud V, et al: AXL Targeting overcomes human lung cancer cell resistance to NK- and CTL-mediated cytotoxicity. Cancer Immunol Res 7: 1789-1802, 2019.

19. Babicki S, Arndt D, Marcu A, Liang Y, Grant JR, Maciejewski A and Wishart DS: Heatmapper: Web-enabled heat mapping for all. Nucleic Acids Res 44 (W1): W147-53, 2016.

20. Oliveros JC: An interactive tool for comparing lists with Venn's diagrams. Publicly available at http://bioinfogp.cnb.csic.es/tools/ venny/index.html.

21. Subramanian A, Tamayo P, Mootha VK, Mukherjee S, Ebert BL, Gillette MA, Paulovich A, Pomeroy SL, Golub TR, Lander ES, et al: Gene set enrichment analysis: A knowledge-based approach for interpreting genome-wide expression profiles. Proc Natl Acad Sci USA 102: 15545-15550, 2005.

22. Liberzon A, Birger C, Thorvaldsdóttir H, Ghandi M, Mesirov JP and Tamayo P: The Molecular Signatures Database (MSigDB) hallmark gene set collection. Cell Syst 1: 417-425, 2015.

23. Durling LJ, Busk L and Hellman BE: Evaluation of the DNA damaging effect of the heat-induced food toxicant 5-hydroxymethylfurfural (HMF) in various cell lines with different activities of sulfotransferases. Food Chem Toxicol 47: 880-884, 2009.

24. Kurashige T, Shimamura M and Nagayama Y: Differences in quantification of DNA double-strand breaks assessed by $53 \mathrm{BP} 1 / \gamma \mathrm{H} 2 \mathrm{AX}$ focus formation assays and the comet assay in mammalian cells treated with irradiation and $\mathrm{N}$-acetyl-Lcysteine. J Radiat Res (Tokyo) 57: 312-317, 2016.

25. Kumari B, Aslam SK, Zaheer S, Adil SO and Shafique K: Systemic inflammatory markers among waterpipe smokers, cigarette smokers, and nonsmokers. J Addict Med 13: 55-60, 2019.

26. Apte RN, Dotan S, Elkabets M, White MR, Reich E, Carmi Y, Song X, Dvozkin T, Krelin Y and Voronov E: The involvement of IL-1 in tumorigenesis, tumor invasiveness, metastasis and tumorhost interactions. Cancer Metastasis Rev 25: 387-408, 2006.

27. Li M, Knight DA, A Snyder L, Smyth MJ and Stewart TJ: A role for CCL2 in both tumor progression and immunosurveillance. OncoImmunology 2: e25474, 2013.

28. Browning L, Patel MR, Horvath EB, Tawara K and Jorcyk CL: IL-6 and ovarian cancer: Inflammatory cytokines in promotion of metastasis. Cancer Manag Res 10: 6685-6693, 2018.

29. Siegmund B, Lehr HA, Fantuzzi G and Dinarello CA: IL-1 beta -converting enzyme (caspase-1) in intestinal inflammation. Proc Natl Acad Sci USA 98: 13249-13254, 2001. 
30. Mani SA, Guo W, Liao MJ, Eaton EN, Ayyanan A, Zhou AY, Brooks M, Reinhard F, Zhang CC, Shipitsin M, et al: The epithelial-mesenchymal transition generates cells with properties of stem cells. Cell 133: 704-715, 2008

31. Bhattacharya R, Mitra T, Ray Chaudhuri S and Roy SS: Mesenchymal splice isoform of CD44 (CD44s) promotes EMT/ invasion and imparts stem-like properties to ovarian cancer cells. J Cell Biochem 119: 3373-3383, 2018.

32. Jayachandran A, Königshoff M, Yu H, Rupniewska E, Hecker M, Klepetko W, Seeger W and Eickelberg O: SNAI transcription factors mediate epithelial-mesenchymal transition in lung fibrosis. Thorax 64: 1053-1061, 2009.

33. Hindriksen S and Bijlsma MF: Cancer stem cells, EMT, and developmental pathway activation in pancreatic tumors. Cancers (Basel) 4: 989-1035, 2012.

34. Tomaskovic-Crook E, Thompson EW and Thiery JP: Epithelial to mesenchymal transition and breast cancer. Breast Cancer Res 11: $213,2009$.

35. Yoshida K, Gowers KHC, Lee-Six H, Chandrasekharan DP, Coorens T, Maughan EF, Beal K, Menzies A, Millar FR, Anderson E, et al: Tobacco smoking and somatic mutations in human bronchial epithelium. Nature 578: 266-272, 2020.

36. Willers H, Gheorghiu L, Liu Q, Efstathiou JA, Wirth LJ, Krause M and von Neubeck C: DNA damage response assessments in human tumor samples provide functional biomarkers of radiosensitivity. Semin Radiat Oncol 25: 237-250, 2015.

37. Holcomb N, Goswami M, Han SG, Clark S, Orren DK, Gairola CG and Mellon I: Exposure of human lung cells to tobacco smoke condensate inhibits the nucleotide excision repair pathway. PLoS One 11: e0158858, 2016.

38. Hang B, Sarker AH, Havel C, Saha S, Hazra TK, Schick S, Jacob P III, Rehan VK, Chenna A, Sharan D, et al: Thirdhand smoke causes DNA damage in human cells. Mutagenesis 28 : 381-391, 2013

39. Lowe DB and Storkus WJ: Chronic inflammation and immunologic-based constraints in malignant disease. Immunotherapy 3: 1265-1274, 2011.

40. Jeong YJ, Oh HK, Park SH and Bong JG: Association between inflammation and cancer stem cell phenotype in breast cancer. Oncol Lett 15: 2380-2386, 2018.

41. Masola V, Carraro A, Granata S, Signorini L, Bellin G, Violi P, Lupo A, Tedeschi U, Onisto M, Gambaro G, et al: In vitro effects of interleukin (IL)-1 beta inhibition on the epithelial-to-mesenchymal transition (EMT) of renal tubular and hepatic stellate cells. J Transl Med 17: 12, 2019.

42. Ling Z, Yang X, Chen X, Xia J, Cheng B and Tao X: CCL2 promotes cell migration by inducing epithelial-mesenchymal transition in oral squamous cell carcinoma. J Oral Pathol Med 48: 477-482, 2019

43. Li J, Zhou Y, Liu Y, Dai B, Zhang YH, Zhang PF and Shi XL: Sorafenib inhibits caspase-1 expression through suppressing TLR4/stat3/SUMO1 pathway in hepatocellular carcinoma. Cancer Biol Ther 19: 1057-1064, 2018.

44. Coppé JP, Patil CK, Rodier F, Sun Y, Muñoz DP, Goldstein J, Nelson PS, Desprez PY and Campisi J: Senescence-associated secretory phenotypes reveal cell-nonautonomous functions of oncogenic RAS and the p53 tumor suppressor. PLoS Biol 6 : 2853-2868, 2008.
45. Khan NA, Lawyer G, McDonough S, Wang Q, Kassem NO, Kas-Petrus F, Ye D, Singh KP, Kassem NOF and Rahman I: Systemic biomarkers of inflammation, oxidative stress and tissue injury and repair among waterpipe, cigarette and dual tobacco smokers. Tob Control, 2019.

46. Qasim H, Alarabi AB, Alzoubi KH, Karim ZA, Alshbool FZ and Khasawneh FT: The effects of hookah/waterpipe smoking on general health and the cardiovascular system. Environ Health Prev Med 24: 58, 2019.

47. Sadek KW, Haik MY, Ashour AA, Baloch T, Aboulkassim T, Yasmeen A, Vranic S, Zeidan A and Al Moustafa AE: Water-pipe smoking promotes epithelial-mesenchymal transition and invasion of human breast cancer cells via ERK1/ERK2 pathways. Cancer Cell Int 18: 180, 2018.

48. Patil S, Subbannayya T, Mohan SV, Babu N, Advani J, Sathe G, Rajagopalan P, Patel K, Bhandi S, Solanki H, et al: Proteomic changes in oral keratinocytes chronically exposed to Shisha (Water Pipe). OMICS 23: 86-97, 2019.

49. Reyes-Caballero H, Park B, Loube J, Sanchez I, Vinayachandran V, Choi Y, Woo J, Edwards J, Brinkman MC, Sussan T, et al: Immune modulation by chronic exposure to waterpipe smoke and immediate-early gene regulation in murine lungs. Tob Control, 2019.

50. Tollerud DJ, Clark JW, Brown LM, Neuland CY, Mann DL, Pankiw-Trost LK, Blattner WA and Hoover RN: Association of cigarette smoking with decreased numbers of circulating natural killer cells. Am Rev Respir Dis 139: 194-198, 1989.

51. Phillips B, Marshall ME, Brown S and Thompson JS: Effect of smoking on human natural killer cell activity. Cancer 56: 2789-2792, 1985 .

52. Newman LS, Kreiss K and Campbell PA: Natural killer cell tumoricidal activity in cigarette smokers and in silicotics. Clin Immunol Immunopathol 60: 399-411, 1991.

53. Motz GT, Eppert BL, Wortham BW, Amos-Kroohs RM, Flury JL, Wesselkamper SC and Borchers MT: Chronic cigarette smoke exposure primes NK cell activation in a mouse model of chronic obstructive pulmonary disease. J Immunol 184 . 4460-4469, 2010.

54. Vu T, Jin L and Datta PK: Effect of cigarette smoking on epithelial to mesenchymal transition (EMT) in lung cancer. J Clin Med 5: E44, 2016.

55. Hoshino Y, Mio T, Nagai S, Miki H, Ito I and Izumi T: Cytotoxic effects of cigarette smoke extract on an alveolar type II cellderived cell line. Am J Physiol Lung Cell Mol Physiol 281: L509-L516, 2001.

56. Jassem J: Tobacco smoking after diagnosis of cancer: Clinical aspects. Transl Lung Cancer Res 8 (Suppl 1): S50-S58, 2019.

This work is licensed under a Creative Commons Attribution-NonCommercial-NoDerivatives 4.0 International (CC BY-NC-ND 4.0) License. 